\title{
Risk Analysis for Metro EPB Shield Tunnel Construction Song Shu-guang ${ }^{1}$, Sun Chao-qun ${ }^{1}$, Ge Yan-hui ${ }^{2}$, Lin Peng ${ }^{1}$, Liu Hong-liang ${ }^{1}$ \\ 1. Geotechnical and Structural Engineering Research Center, Shandong University, Jinan 250061, China. \\ 2. School of Civil Engineering,Shandong Jiao Tong University, Jinan 250357, China.
}

Keywords: earth pressure balance shield; fuzzy comprehensive evaluation; risk analysis

\begin{abstract}
For the characteristics of metro earch pressure balance (EPB) shield tunnel construction, first of all, the EPB shield tunnel is analyzed in detail, and their causes, impacts and mitigation measures are also studied accordingly. Then the risk factors of shield tunnel construction by using the idea of system engineering are identified, and its levels are analyzed, and safety assessment index system is structured. The case history of risk control for EPB shield tunnel in Changsha confirmed the rationality and feasibility of the suggested risk control measures.
\end{abstract}

\section{Introduction}

The current domestic large cities have started to build the underground railway in China, because most of the cities are soft soil mass, the underground construction safety problems become one of the most important issue construction units concerned. In this paper, based on the analysis of the characteristics of the metro project risk, systematic analysis of the earth pressure balance shield tunnel construction risk source, this paper discusses the reasons and the corresponding risk control measures. Combined with engineering instance verified the rationality of risk analysis, for the same type of construction site safety management has certain reference significance.

\section{The fuzzy comprehensive evaluation model}

Fuzzy comprehensive evaluation by constructing fuzzy subsets of grade, to reflect the fuzzy index quantify evaluation objects (that is, to determine the membership degree), and then, by using fuzzy transform principle for integrated operation of the various indicators of the evaluation results are obtained. Specific steps are as follows:

(1)Establish evaluation object factor sets.

The large shield construction in and out of the tunnel as a collection of multiple factors, called $\mathrm{u} 1, \mathrm{u} 2, \ldots, \mathrm{u}_{\mathrm{k}}$ which show the construction condition attributes as the evaluation factor set $\mathrm{U}, \mathrm{U}$ $=\left\{\mathrm{u} 1, \mathrm{u} 2, \ldots, \mathrm{u}_{\mathrm{k}}\right\}$

(2)The weight distribution of evaluation factors.

According to various factors, to the influence of shield construction risk condition in and out of the tunnel size, using analytic hierarchy process (APH), determine the weight distribution. A weighted fuzzy vector is:

$$
\vec{A}=\left(a_{1}, a_{2}, \ldots, a_{n}\right)
$$

(3) Determine the evaluation set V

On the risk status of the shield in and out of the tunnel, the establishment of evaluation set is as follows:

$\mathrm{V}=\left\{v_{1}, v_{2}, \ldots, v_{m}\right\}$

(4) Assign each factor weight

According to each sub factors influence on the evaluation set $\mathrm{V}$, the weight distribution as $\left(w_{i 1}, w_{i 2}, \ldots w_{i k}\right), w$ is the son factor fuzzy vector.

(5) Establishing single factor evaluation

Establishing single factor evaluation, namely, to establish a fuzzy mapping from $U$ to $F(V)$ 


$$
\begin{aligned}
& f: U \rightarrow F(V), \quad \forall u_{i} \in U \\
& u_{i} \mid \rightarrow f\left(u_{i}\right)=\frac{r_{i 1}}{v_{1}}+\frac{r_{i 2}}{v_{2}}+\cdots+\frac{r_{i m}}{v_{m}} \\
& 0 \leq r_{i j} \leq 1,1 \leq i \leq \mathrm{n}, 1 \leq j \leq \mathrm{m} ;
\end{aligned}
$$

By $f$ can deduce the fuzzy relation, fuzzy relationship matrix, it is a single factor evaluation matrix:

$$
R=\left[\begin{array}{cccc}
r_{11} & r_{12} & \cdots & r_{1 n} \\
r_{21} & r_{22} & \cdots & r_{2 n} \\
\cdots & \cdots & \cdots & \cdots \\
r_{m 1} & r_{m 2} & \cdots & r_{m m}
\end{array}\right]
$$

(6) The calculation of fuzzy comprehensive evaluation matrix

According to shield construction in and out of the hole risk matrix and fuzzy matrix, the relationship between various factors can be $(U, V, R)$ consisting of a comprehensive evaluation model, namely $\vec{B}=\vec{A} \bullet \vec{R}$

$$
\begin{aligned}
& \vec{B}=\left[b_{1}, b_{2}, \cdots, b_{n}\right]=\left[a_{1}, a_{2}, \cdots, a_{m}\right] \times\left[\begin{array}{cccc}
r_{11} & r_{12} & \cdots & r_{1 n} \\
r_{21} & r_{22} & \cdots & r_{2 n} \\
\cdots & \cdots & \cdots & \cdots \\
r_{m 1} & r_{m 2} & \cdots & r_{m m}
\end{array}\right] \\
& b_{j}=\bigvee_{i=1}^{n}\left(a_{i} \wedge r_{i j}\right), \quad(i=1,2, \cdots, m)
\end{aligned}
$$

If the evaluations result $\sum_{j=1}^{m} b_{j} \neq 1$, the result was normalized processing.

\section{Project summary and risk identification}

\section{Project summary.}

Changsha subway tunnel shield interval mileage DK1 + $800 \sim$ DK6 + 562, the total length of 4762 $\mathrm{m}$, using two $\Phi 9.33 \mathrm{~m}$ of earth pressure balance shield tunneling. Left and right line of shield advance in both the railway under construction in all five times. Geology mainly argillaceous siltstone. Buried groundwater types according to its dispersion characteristics are divided into the upper perched water, pore water and strong to the weak weathered bedrock fissure water.

\section{Risk factor.}

Construction risk caused by risk factor as the inducing factors of construction risk, mainly including the following possible factors:

(1) The rationality of the cutter tool selection

If the cutter tool configuration is not reasonable, will, because of the large sandy pebble formation grinding peck sex cause tool and serious wear of cutter.

(2) The selection of construction parameters

Construction parameters is the main factor to guarantee the stability of excavation face, at the same time, due to the shield in front of the existence of uncertain geologic factors, improper construction parameter selection, it is easy to appear the excavation face the risk of collapse.

(3) Shield equipment failure

Shield equipment failure is mainly divided into system fault, propulsion system failure, grouting system failure, slag system failure.

The main risk of shield tunnel construction.

The main risk of shield tunnel construction in Changsha are: the settlement of the ground subsidence $\left(\mathrm{u}_{1}\right)$, both the railway and the displacement $\left(\mathrm{u}_{2}\right)$, building destruction $\left(\mathrm{u}_{3}\right)$, underground 
pipeline damage $\left(\mathrm{u}_{4}\right)$, shield machine cutter head stuck $\left(\mathrm{u}_{5}\right)$, excavation axis deviation $\left(\mathrm{u}_{6}\right)$, large fault $\left(\mathrm{u}_{7}\right)$ shield, casualties $\left(\mathrm{u}_{8}\right)$, shield machine cutter damage shield $\left(\mathrm{u}_{9}\right)$, confidential sealing system failure $\left(\mathrm{u}_{10}\right)$, etc.

\section{Risk analyses}

\section{Determine the risk events and consequences evaluation sets two domains.}

Set to 10 kinds of major risk events, form event risk factors set $U=\left\{u_{1}, u_{2}, \cdots u_{10}\right\}$. The repercussions of evaluation of risk events, generally divided into five kinds of circumstances, constitute the consequences of risk events evaluation set $V=\left\{\right.$ negligible $\left(v_{1}\right)$, should be considered $\left(v_{2}\right)$, serious $\left(v_{3}\right)$, very big $\left(v_{4}\right)$, catastrophic $\left.\left(v_{5}\right)\right\}$.

\section{Determine the contestant event risk factors weights.}

0-1 score cumulative method, this article USES namely after experts score for each risk events, take the average, each contestant factor weights values, are shown in table 1.

Table 1 Excavation scheme of cavern group

\begin{tabular}{cccccccccccccc}
\hline $\begin{array}{c}\text { Contestant } \\
\text { factor }\end{array}$ & $u_{1}$ & $u_{2}$ & $u_{3}$ & $u_{4}$ & $u_{5}$ & $u_{6}$ & $u_{7}$ & $u_{8}$ & $u_{9}$ & $u_{10}$ & $\begin{array}{c}\text { The } \\
\text { factor } \\
\text { score }\end{array}$ & $\begin{array}{c}\text { Weighted } \\
\text { score }\end{array}$ & $\begin{array}{c}\text { Weight } \\
\text { value }\end{array}$ \\
\hline$u_{1}$ & $\times$ & 1 & 1 & 1 & 0 & 0 & 1 & 0 & 1 & 1 & 6 & 5 & 0.125 \\
$u_{2}$ & 1 & $\times$ & 1 & 1 & 0 & 0 & 1 & 0 & 1 & 1 & 6 & 5 & 0.125 \\
$u_{3}$ & 1 & 1 & $\times$ & 1 & 0 & 0 & 1 & 1 & 1 & 1 & 7 & 8 & 0.2 \\
$u_{4}$ & 1 & 1 & 1 & $\times$ & 0 & 0 & 1 & 0 & 1 & 1 & 6 & 5 & 0.125 \\
$u_{5}$ & 0 & 0 & 0 & 0 & $\times$ & 0 & 1 & 0 & 1 & 1 & 3 & 2 & 0.05 \\
$u_{6}$ & 0 & 0 & 0 & 1 & 0 & $\times$ & 1 & 0 & 0 & 0 & 2 & 1 & 0.025 \\
$u_{7}$ & 1 & 1 & 1 & 0 & 0 & 1 & $\times$ & 1 & 1 & 1 & 7 & 8 & 0.2 \\
$u_{8}$ & 0 & 0 & 1 & 0 & 0 & 0 & 1 & $\times$ & 0 & 1 & 3 & 2 & 0.05 \\
$u_{9}$ & 1 & 0 & 1 & 0 & 1 & 0 & 0 & 0 & $\times$ & 1 & 4 & 3 & 0.075 \\
$u_{10}$ & 0 & 0 & 1 & 0 & 0 & 0 & 1 & 0 & 0 & $\times$ & 2 & 1 & 0.025 \\
\hline
\end{tabular}

The contestant event risk factors weights vector as follows:

$\vec{A}=\left\{a_{1}, a_{2}, \cdots a_{10}\right\}=\{0.125,0.125,0.2,0.125,0.05,0.025,0.2,0.05,0.075,0.025\}$.

Calculating the fuzzy matrix $\vec{R}$.

$$
\vec{R}=\left[\begin{array}{lllll}
0 & 0 & 0.1 & 0.1 & 0.7 \\
0 & 0 & 0 & 0.1 & 0.8 \\
0 & 0 & 0.1 & 0.2 & 0.6 \\
0 & 0 & 0.2 & 0 & 0.8 \\
0.7 & 0.2 & 0.3 & 0 & 0 \\
0.8 & 0.1 & 0.2 & 0 & 0 \\
0.7 & 0.2 & 0.1 & 0 & 0.1 \\
0 & 0 & 0 & 0.1 & 0.8 \\
0.1 & 0.2 & 0.2 & 0.2 & 0.2 \\
0.2 & 0.1 & 0.3 & 0.1 & 0.3
\end{array}\right]
$$


Comprehensive evaluation vector calculation $\vec{B}$.

$\vec{B}=\vec{A} \bullet \vec{R}=\left(b_{1}, b_{2}, \cdots b_{n}\right)=(0.2075,0.07,0.12,0.0875$, and 0.49$) ;$

$C_{f}=\vec{B} \bullet \vec{R}^{T}=\{0.36375,0.40075,0.3235,0.416,0.19525,0.197,0.22025,0.40075,0.17425,0.2402\}$

The normalized processing, are:

$C_{f}^{\prime}=\{0.784,0.937,0.617,1,0.087,0.094,0.19,0.937,0,0.273\}$.

According to the calculation of the comprehensive evaluation value, include 10 kinds of event risk factors consequences evaluation set a defined five levels, the specific division are shown in table 2.

Table2 Risk factors for grading

\begin{tabular}{cccccc}
\hline Level & 1 & 2 & 3 & 4 & 5 \\
\hline Risk factors for the event & $\boldsymbol{u}_{5}, \boldsymbol{u}_{6}, \boldsymbol{u}_{7}, \boldsymbol{u}_{9}, \boldsymbol{u}_{10}$ & $\boldsymbol{u}_{3}$ & $\boldsymbol{u}_{1}$ & - & $\boldsymbol{u}_{2}, \boldsymbol{u}_{4}, \boldsymbol{u}_{8}$
\end{tabular}

from the chart, both railway settlement $\left(u_{2}\right)$ 、 horizontal displacement $\left(u_{4}\right)$ and casualties $\left(u_{8}\right)$ are level 5 , as the biggest risk events; Followed by the surface subsidence is too large $\left(\boldsymbol{u}_{3}\right)$ risk of grade 3; Building damage $\left(\boldsymbol{u}_{3}\right)$, the risk level of 2; Then the rest risk levels are 1, to a negligible risk event.

\section{Conclusions}

(1) According to the analytic hierarchy structure model, constructs the various levels of fuzzy judge Matrix. After judging matrix consistency, the expert fuzzy mutual is given Complementary judgment matrix is transformed into a satisfying consistency of fuzzy judgment matrix.

(2) Safety risk analysis method based on fuzzy analytic hierarchy process (AHP), overcome the limitations of the risk assessment matrix or the analytic hierarchy process (AHP), and can more objectively assess the safety situation of subway shield tunnel, to have the key to improve the shield tunnel accident security has a positive effect.

\section{Acknowledgements}

The research was supported by the National Natural Science Foundation of China (No. 41302225). The supported was gratefully acknowledged.

\section{References}

[1] Saaty.The Analytic Hierarchy Process [M] .New York: McGraw Hill Inc, 1980.

[2] SAGASETA C. Analysis of untrained soil deformation due to ground loss [J]. Geotechnique, 1988,38(4):647-649.

[3] VERRUIJT A,BOOKER J R. Surface settlements due to deformation of a tunnel in an elastic half plane[J]. Geotechnique,1996,46(4):753-756.

[4] PARK K H. Elastic solution for tunneling-induced ground movements in clays[J]. International Journal of Geomechanics,2004,4(4):310-318.

[5]PARK K H. Analytical solution for tunneling-induced ground movement in clays[J].Tunneling and Underground Space Technology,2005,20(3):249-261.

[6] LEE K M,ROWE R K,LO K Y. Subsidence owing to tunneling I:estimating the gap parameter[J]. Canadian Geotechnical Journal, 1992, 29(6):929-940.

[7] SAGASETA C. Analysis of undrained soil deformation due to ground loss [J]. Geotechnique, 1987,37(3):301-320. 